\title{
Estimation of Frequency Modulated Radio Transmitter Power Required to Cover a Particular Distance Based on Available Radio Receiver Sensitivity and Desired Signal Range
}

\author{
*Iyen, C. ${ }^{1}$, Umar, I. ${ }^{2}$, Wansah, J.F. ${ }^{1}$, Jaafaru, S. ${ }^{3}$ Iseh, A. ${ }^{1}$, Akeredolu, B. ${ }^{1}$, Ewa, $\mathbf{I}^{2}$ \\ ${ }^{I}$ Department of Pure and Applied Physics, Federal University Wukari, Taraba State \\ ${ }^{2}$ Department of Physics, Nasarawa State University, Keffi, Nasarawa State \\ ${ }^{3}$ Shedda Science and Technology Complex (SHESTCO), Gwagwalada, Abuja.
}

*Corresponding Author: Iyen, C, Department of Pure and Applied Physics, Federal University Wukari, Taraba State, Nigeria

\begin{abstract}
Effective communication is a very important aspect of any community. Radio communication provides a means for fast and easy circulation of information. Frequency Modulated (FM) Transmitters currently in use in the country are procured blindly without first investigating to know the required power of the transmitter to be procured, this leads to spending money on a transmitter that is either too powerful for the purpose or not powerful enough. In this research, the required output power of the transmitter required to cover the active areas of Federal University Wukari was computed by using the relationship between output power, receiver sensitivity and required distance. It was discovered that a radio transmitter with an output power of $63 \mathrm{~mW}(18 \mathrm{dBm})$ can cover all active parts of the school which was discovered to be $1375 \mathrm{~m}$ radius. It was concluded that the methods used in this study can be used to estimate required output power during transmitter design and procurement.
\end{abstract}

Keywords: Radio transmitter, communication, frequency modulation, receiver sensitivity, transmitter power

\section{INTRODUCTION}

Frequency Modulated (FM) radio transmitters are used to transmit voice signals across/over a range within which individuals can receive the signals with their FM radio receiver. The importance of such a communication medium within any community or organisation cannot be over emphasized as it provides a means of disseminating important information across the community and serves as a facilitator for other fun and exciting activities within the community. In electronics and telecommunications, a transmitter or radio transmitter is an electronic device which with the aid of an antenna produces radio waves. The transmitter itself generates a radio frequency alternating current which is applied to the antenna. When the antenna is excited by the alternating current, it radiates radio waves. In addition to their use in broadcasting, transmitters are necessary components parts of many electronic devices that communicate by radio such as cell phones, wireless computer networks, bluetooth enabled devices, garage door openers, two- way radio and broadcast stations [1].

Communication can be defined as the process of transmitting information and common understanding from one person to another [2].However, when the distance between the communicating parties becomes very large, the transmission of signals over long distances such as by telegraph, radio or television is called telecommunication [3]. This form of communication is not limited to sound alone and can be applied for computer data, videos and pictures [4].

A number of approaches have been taken with regards to estimating radio transmitter range and power. [5] discussed how mathematical models are used to estimate transmitter range in wireless network. [6] discussed how antenna height can be adjusted to reduced path loss and hence improve the range of a radio transmitter, [7] studied the effect of other factors like antenna tilt on transmitter coverage. [8] discussed the use of the Friis transmission equation for estimation of required transmitter power. 


\section{Materials ANd Methods}

\subsection{Determination of the Sensitivity (E) of Available Radio Receivers}

The sensitivity of the available radio receivers was gotten through an open market survey by checking through the technical data sheet of the most common radio receivers used in the study area and the readings were tabulated. The radio receiver with the lowest sensitivity was used for the computation.

\subsection{Estimation of the Distance (D) to be Covered by the Radio Transmitter}

Measurement is the assignment of numbers to objects or events. It is a cornerstone of most natural sciences, technology, economics and quantitative research in other social sciences. The desired transmitter range was achieved by using Global Positioning System (GPS) readings. The GPS is a space based navigation system that provides location and time information in all weather conditions [9], anywhere on or near the earth where there is an unobstructed line of sight [10]. GPS is globally used for tracking and navigation purpose [11]. GPS has been applied in vehicle security [12], computer science and wireless video processing [13], location awareness and navigation [14] and health related physical activities [15]. The range to be covered by the radio receiver was achieved by getting satellite location of the point in which the transmitter will be located within the school and also locating the furthest desired point where the signals transmitted are to be received. The distance between the activity center of the main campus of the Federal University Wukari and the furthest satellite boy's hostel was measured using the Field Area Measurement software which can be downloaded on any android device that is equipped with a GPS.

\subsection{Computation of the Desired Transmitter Power}

The desired transmitter power was estimated by using the formular given in equation (1):

$$
E=\frac{\sqrt{30 P_{t}}}{d}
$$

By making $P_{t}$ the subject of formular we obtain:

$P_{t}=\frac{E^{2} d^{2}}{30}$

where $P_{t}$ is the required transmitter power

$E$ is the sensitivity of available radio receivers

$d$ is the range or distance to be covered by the transmitter

\section{RESULTS AND DISCUSSION}

\subsection{Determination of the Sensitivity of Available Radio Receivers}

Receiver sensitivity is normally taken as the minimum input signal $\left(S_{\min }\right)$ required to produce a specified output signal having a specified signal-to-noise $(\mathrm{S} / \mathrm{N})$ ratio and is defined as the minimum signal-to-noise ratio times the mean noise power and is given by equation (3)

$S_{\min }=(S / N)_{\min } K T_{o} B(N F)$

Where $S_{\min }=$ Minimum Signal-to-Noise ratio needed to process a signal

$\mathrm{NF}=$ Noise Figure/ Noise Factor

$\mathrm{K}=$ Boltzmann's Constant $=1.38 \times 10^{-23} \mathrm{Joule} / \mathrm{K}$

$\mathrm{T}_{\mathrm{o}}=$ Absolute temperature of the receiver input in Kelvin

$\mathrm{B}=$ Receiver bandwidth

The sensitivity of radio receivers can be gotten from technical data sheets that come with the radio receivers. Table 1 shows the sensitivity values obtained for available radio receivers in the vicinity of the project site. From Table 1, the sensitivity for the computation is therefore $10 \mu \mathrm{V}$ 
Estimation of Frequency Modulated Radio Transmitter Power Required To Cover a Particular Distance Based on Available Radio Receiver Sensitivity and Desired Signal Range

Table1. Sensitivity of Available Radio Receivers

\begin{tabular}{|l|l|c|}
\hline S/NO & NAME & SENSITIVITY \\
\hline 1. & X-BASS AM/FM/SW1-2 4 BAND RADIO & $10 \mu \mathrm{V}$ \\
\hline 2. & KCHIBO FM/MW/SW 1-6 8 BANDS \& MP3 RADIO & $10 \mu \mathrm{V}$ \\
\hline 3. & KCHIBO FM/TV1/MW/SW 1-9 12 BANDS RECEIVER & $10 \mu \mathrm{V}$ \\
\hline 4. & KCHIBO FM/MW/SW 1-18 20 BAND RECEIVER & $20 \mu \mathrm{V}$ \\
\hline 5. & KCHIBO FM/MW/SW1/SW2 4 BAND RECIEVER & $20 \mu \mathrm{V}$ \\
\hline 6. & KCHIBO FM/MW/SW1-10 HIGH SENSITIVITY RADIO & $20 \mu \mathrm{V}$ \\
\hline
\end{tabular}

\subsection{Transmitter Distance (D)}

From the Global Positioning System (GPS), using the Fields Area Measurement Software, a total distance of $1.373 \mathrm{~km} \equiv 1373 \mathrm{~m}$ was obtained as the total range to be covered by the transmitter: Plate 1 shows the diagram of the readings gotten from the software.

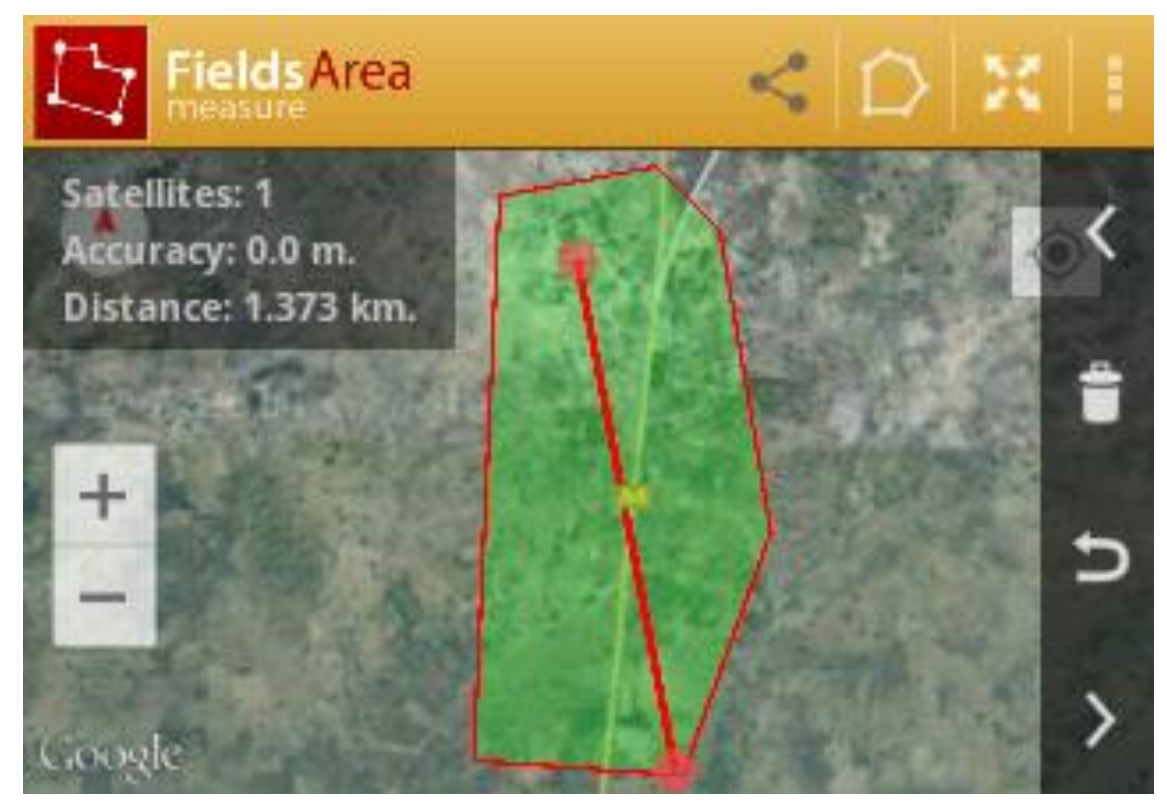

Fig3.1. Estimating the Transmitter Range using Fields Areas Measurement

\subsection{Required Output Power $P_{t}$ of the Radio Transmitter}

By substituting the radio receiver sensitivity $\mathrm{E}$ gotten in equation and the desired distance obtained in into equation (2) we obtain:

$P_{t}=\frac{\left(20 \times 10^{-6}\right)^{2} \times(1375)^{2}}{30}$

The distance is $1375 \mathrm{~m}$. However, According to [10] the formula represented in equation (1) has an efficiency of $1 \%$, this implies that we will be calculating for a distance of $137500 \mathrm{~m}$ substituting this into our equation (2) we obtain:

$$
\begin{gathered}
P_{t}=\frac{\left(10 \times 10^{-6}\right)^{2} \times(137500)^{2}}{30} \\
P_{t}=\frac{1.89}{30}=0.063 \mathrm{~W}=63 \mathrm{~mW}
\end{gathered}
$$

Converting the estimated output power from $\mathrm{mW}$ to $\mathrm{dBm}$ we obtain:

Power in $\mathrm{dBm}=10 \log _{10}$ (Power in milliWatt)

$\Rightarrow d B m=10 \log _{10}(63)$

$d B m=10 \times 1.799=17.99 \mathrm{dBm} \approx 18 \mathrm{dBm}$

The transmitter power $P_{t}$ expressed in equation (4) shows that a transmitter power of $63 \mathrm{~mW}$ is required to covered the current active areas of Federal University Wukari which is about $1.375 \mathrm{~km}$ radius. 


\section{DISCUSSION}

[16] built an FM transmitter which transmits at a frequency of $98.2 \mathrm{MHz}$ with an output power of 6.3 $\mathrm{dBm}$. His transmitter was capable of covering a distance of 500 metres. Likewise, [10] built an FM transmitter which transmits at a frequency of $107.2 \mathrm{MHz}$ with an output power of $3.98 \mathrm{dBm}$ which was capable of transmitting signals to be received at 206 metres radius of the transmitter location. Both of these transmitters were not constructed using equation (2)

The works of both [16] and [10] confirms that the formula represented in equation (2) can be used to estimate the transmitter power required to cover a given distance before the transmitter is constructed.

\section{CONCLUSION}

The result of this research work showed that the formula represented in equation (2) can be used to estimate transmitter power required to cover predetermined area or distance. It also confirmed that the methodology or approach utilized in this research work can be followed to estimate transmitter power. It was discovered that the total active area of the school which is $1375 \mathrm{~m}$ can be covered with a radio transmitter with output power of $18 \mathrm{dBm}$

\section{ACKNOWLEDGEMENT}

The authors acknowledge the Department of Pure and Applied Physics of Federal University Wukari and the Department of Physics of Nasarawa State University Keffi for allowing us access to their physics laboratories to perform experiments.

\section{REFERENCES}

[1] Acharya, M., Biswas, R., (2015). 'Design and Implementation of Frequency modulated transmission and reception of speech signal and FPGA based enhancement.' ACCENTS Transactions on Image Processing and Computer Vision, 1(1): 12-22.

[2] Keyton, J. (2011). Communication and Organizational Structure: A Key to Understanding work experience. Sage, Thousand Oaks, CA. Pp. 250-280

[3] Freeman, R. (1999). Telecommunications. Fundamentals of Telecommunications. John Wiley \& Sons, Inc., New York. p.100-105

[4] Simpson, J., Weiner, E., (1989). Telecommunication. Oxford English Dictionary. Oxford University Press, Oxford. Pp 500-509

[5] Sharma K.P \& Singh R.K. (2012). Cell Coverage Area and Link Budget Calculations in GSM System. International Journal of Modern Engineering Research (IJMER). 2(2): Pp. 170-176

[6] Sharma, S. and Uppal, R.S. (2012). RF Coverage Estimation of Cellular Mobile System. International Journal of Engineering and Technology. 3(6): Pp. 110-115

[7] Akpado K.A., Oguejio for O.S., Ezeagwu, C.O. and Okolihe, A.U. (2013). Investigating the Impacts of Base Station Antenna Height, Tilt and Transmitter Power on Network Coverage. International Journal of Engineering Science Invention. 2(7): Pp. 32-38

[8] Atmel (2015). 'Range Calculation for $300 \mathrm{MHz}$ to $1000 \mathrm{MHz}$ Communication Systems. Atmel Application Note. Pp. 1-16

[9] Hoque, M.Z. (2016). 'Basic Concept of GPS and its Application.' IOSR Journal of Humanities and Social Sciences. 21(3): Pp. 31-37

[10] Collinson, A. (2009). Estimating transmitter distance. Retrieved from: http://www.zen22142. zen.co.uk/ Analysis/efftxd.htm. 14/06/2016

[11] Damani A, Shah H., Shah K \& Vala M. (2015). Global Positioning System for Object Tracking. International Journal of Computer Applications. 109(8): Pp 40-45

[12] Verma, P \& Bhatta J.H. (2013). 'Design and development of GPS-GSM Based Tracking System with Google Map Based Monitoring. International Journal of Computer Science, Engineering and Applications (IJCSEA). 3(3); Pp 100-105

[13] Singal, P. \& Chhillar R.S. (2014). A Review on GPS and it's Applications in Computer Science.' International Journal of Computer Science and mobile computing. 3(5): Pp. 1295-1302

[14] Hwang, S and Yu, D. (2012). 'GPS localization Improvement of Smart Phones built in Sensors'. International Journal of Smart Phones. 6(3):Pp. 105-112 
Estimation of Frequency Modulated Radio Transmitter Power Required To Cover a Particular Distance Based on Available Radio Receiver Sensitivity and Desired Signal Range

[15] Duncan M.J. Bandland H.M. \& Mummery, W.K. (2008). Applying GPS to enhance understanding of Transport related Physical Activity. Journal of Science and Medicine in Sport. 10(10): Pp. 11-16

[16] Pearce, D. (Director). (2012). I show you how to build a spy bug radio [Motion Picture]. Retrieved from: https://www.onlinevideotutorials.com/build-a-radio-transmitter.html. 25/05/2015

Citation: Iyen, C. et al. (2017). Estimation of Frequency Modulated Radio Transmitter Power Required To Cover a Particular Distance Based on Available Radio Receiver Sensitivity and Desired Signal Range, International Journal of Innovative Research in Electronics and Communications (IJIREC), 4(2), pp.12-17, DOI: http:// dx.doi.org/10.20431/2349-4050.0402003

Copyright: (C) 2017 Iyen, C. This is an open-access article distributed under the terms of the Creative Commons Attribution License, which permits unrestricted use, distribution, and reproduction in any medium, provided the original author and source are credited 